\section{Quantitative Technique for Measuring Volatile Components of Baked Sweetpotatoes}

\author{
Jyh-Bin Sun \\ Department of Horticulture, University of Georgia, Athens, GA 30602-7273
}

Ray F. Severson

Phytochemical Research Unit, Russell Research Center, U.S. Department of Agriculture, Athens, GA 30612

\author{
Stanley J. Kays \\ Department of Horticulture, University of Georgia, Athens, GA 30602-7273
}

Additional index words. genetic resources, flavor, odor, Ipomoea batatas

\begin{abstract}
We describe a relatively simple collection procedure for quantifying volatiles in baked sweetpotato [Ipomoea batatas (L.) Lam.]. Volatiles formed during baking 'Jewel' and 'Centennial' sweetpotatoes at $204 \mathrm{C}$ were purged from a baking vessel with $\mathrm{He}$ or a $\mathrm{He}$ $\mathrm{O}_{2}$ mixture, collected in cold methylene chloride, and reduced in volume using a KudernaDanish concentrator. Volatile components were quantified by capillary gas chromatography and characterized using gas chromatographic-mass spectrometer analysis. Quantitatively, the major components were identified as 2-furaldehyde; 2-furanmethanol; benzaldehyde; 5-methyl-2-furfural; phenylacetaldehyde; 3-hydroxy-2-methyl$4 \mathrm{H}$-pyran-4-one; 2,3-dihydro-3,5-dihydroxy-6-methyl-4 $\mathrm{H}$-pyran-4-one; and 5hydroxy-methyl-2-furancarboxaldehyde. Some quantitatively minor compounds were also identified. The volatile collection system is reproducible for quantitative comparisons among breeding lines.
\end{abstract}

Worldwide, the sweetpotato is a major staple crop, though its popularity is declining (Horton, 1988). One reason for this decline is thought to be the dominant flavor of the cooked product (Kays, 1985). Unlike most staple crops that have a low flavor impact (e.g., cassava, rice, white potato), the dominant flavor of the sweetpotato minimizes the flavor diversity of the dishes that can be prepared. Characterizing the major flavor components of baked sweetpotato would assist in developing both traditional and new flavor types. In conventional sweetpotato breeding programs, flavor

Received for publication 16 Sept. 1992. Accepted for publication 3 July 1993. The cost of publishing this paper was defrayed in part by the payment of page charges. Under postal regulations, this paper therefore must be hereby marked advertisement solely to indicate this fact. is one of the last traits selected, hence $\approx 99 \%$ of the seedling population has typically been discarded before flavor is assessed (Kays, 1988). The low priority for flavor is due to the inability to screen large numbers of progenies. The availability of an accurate analytical measure of critical flavor components that is amenable to assessing large numbers of breeding lines would accelerate selection for improved and/or alternative flavor types.

Flavor is composed of taste and aroma, both of which are known to be primary factors in selecting foods. The taste of cooked sweetpotato is derived mainly from mono-and disaccharides. Of the primary sugars, sucrose, fructose, and glucose are present in the raw root, while maltose is formed with the hydrolysis of starch during cooking (Horvat et al., 1991; Kays and Horvat, 1984; Picha, 1985, 1986). The characteristic aroma of cooked sweetpotato is thought to be derived from several volatiles, although the critical compounds have yet to be identified.

Initial reports on the volatile components of baked 'Jewel' sweetpotatoes (Purcell et al., 1980) indicated the presence of at least 30 compounds. Subsequently, additional volatiles were identified and distinct qualitative differences between cultivars were established (Horvat et al., 1991; Kays and Horvat, 1983, 1984; Tiu et al., 1985). Each of these studies focused on identification rather than quantification, the latter being an essential requisite for an analytical approach to screening progeny from breeding programs on the basis of flavor. None of the volatile components identified thus far (Kays, 1988) have been found to impart the characteristic aromatic properties of the sweetpotato.

In previous studies, volatile compounds were collected after baking using either a purge and trap (Tenax) technique (Purcell et al., 1980; Tiu et al., 1985) or steam distillation followed by solvent partitioning (Horvat et al., 1991; Kays and Horvat, 1984), neither of which is ideally suited to quantification. Our objective was to develop a rapid, accurate technique for quantifying and qualifying the volatiles from cooked sweetpotato breeding lines and progeny.

'Jewel' and 'Centennial' sweetpotatoes grown at the Univ. of Georgia Horticulture Farm were harvested, cured [29C, 95\% relative humidity (RH)] for 7 days, and stored at 15C, $85 \%$ RH until use. Methylene chloride (J.T. Baker, Phillipsburg, N.J.) was used as the solvent and redistilled with a Kuderna-Danish evaporator/concentrator before use. Reagents and standards were obtained from commercial sources (2-furan-carboxaldehyde, 3-hydroxy2-methyl-4 $H$ - pyran-4-one, Aldrich Chemical Co., Milwaukee; 2-furanmethanol, Matheson Coleman \& Bell Manufacturing Chemists, Norwood, Ohio; 5-hydroxymethyl-2furancarboxaldehyde, Sigma Chemical Co., St. Louis). Mass spectral data references were obtained from the Wiley/NBS registry of mass spectral data (McLafferty, 1988). Samples were baked in a 1-liter glass sample container (Fig. 1 ), and the volatiles trapped in a glass column ( $3 \mathrm{~cm}$ in diameter $\times 75 \mathrm{~cm}$ high) containing ice-cooled methylene chloride. Teflon tubing was used to connect the glassware to the carrier gas regulator. 


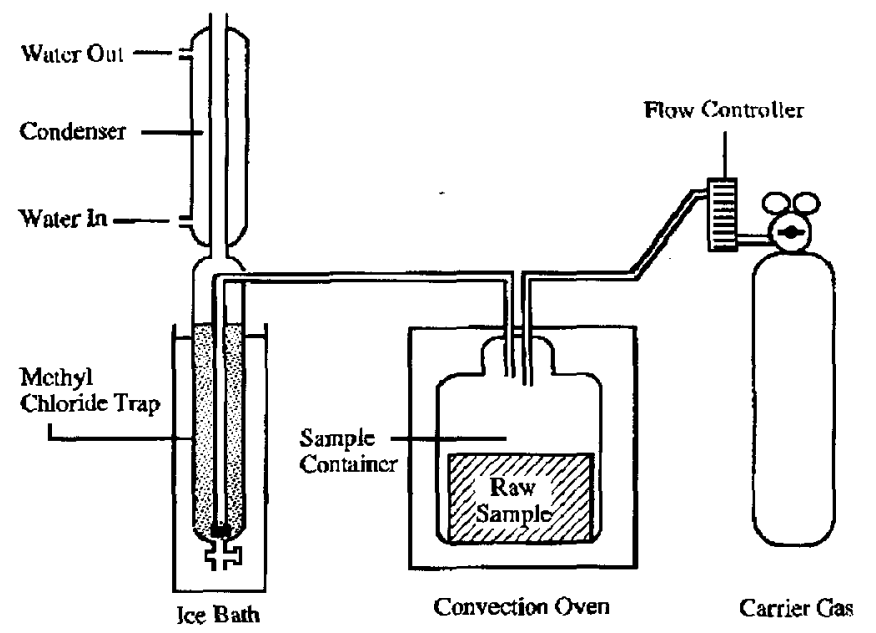

Fig. 1. Baking and collection apparatus for volatile compounds produced by sweetpotato storage roots during baking.

Three cross-sectional cores $(1.7 \mathrm{~cm}$ id. $\times 3$ $\mathrm{cm})$ were removed from individual 'Jewel' roots. Eight roots (24 cores) made up a replication, giving samples of equivalent weights (average $160.9 \mathrm{~g}$ ) and surface areas $\left(20.6 \mathrm{~cm}^{2}\right)$. A total of 32 roots were used for the four replications. 'Centennial' roots were selected and prepared in the same manner. The surface area and number of cores were as previously described; however, the average weight of each replication was $151.4 \mathrm{~g}$.

Baking and volatile collection. Individual sample replications were placed inside a specially constructed 1-liter glass container in an electric convection oven. A stream of He carrier gas $\left(34 \mathrm{ml} \cdot \mathrm{min}^{-1}\right)$ was passed through the jar into a methylene chloride solvent trap next to the oven to collect volatile compounds (Fig. 1). Volatiles were swept from the sample container with the carrier gas that was bubbled through an ice-cooled column of redistilled methylene chloride. A fritted glass gas dispersion tube was fitted inside the trap to minimize the size of carrier gas bubbles moving upward through the solvent. The sample was heated to 204C and held at that temperature for a total baking and volatile collection time of $70 \mathrm{~min}$.

Ninety milliliters of methylene chloride containing $54 \mu \mathrm{g}$ ethyl benzoate/ml (internal standard) was used to trap the volatiles. An additional $10 \mathrm{ml}$ of solvent was used to rinse the trapping chamber at the end of the collection period. The composite sample was concentrated using a Kudema-Danish evaporator/concentrator, in which the sample flask was heated using a steam bath. The sample ( 80 $\mathrm{ml}$ ) was reduced to $3 \mathrm{ml}$, and $5-\mu \mathrm{l}$ aliquots were immediately chromatographed.

Gas chromatographic (GC) analysis and characterization. Samples were chromatographed on a thick-coated OV-225 fused silica capillary column $(0.3 \mathrm{~mm}$ id. $\times 30 \mathrm{~m})$ in a Hewlett Packard (Avendale, Pa.) 5880A gas chromatography with a split-splitless injection port temperature at $200 \mathrm{C}$ and a flame ionization detector at $250 \mathrm{C}$. The sample was injected in the splitless mode (30C) with a purge time of $1 \mathrm{~min}$ and held at that temperature for $2 \mathrm{~min}$, after which the oven temperature was increased to $200 \mathrm{C}$ at $3 \mathrm{C} / \mathrm{min}$ followed by holding at 200C for $10 \mathrm{~min}$. Individual compounds were identified using an HP 5985B mass spectrometer (MS). The MS conditions were: OV-225 capillary column; GC/MS interface zone at 300C; ion source at 200C; scan range, 35-400 atomic mass units; electron energy, $70 \mathrm{eV}$; multiplier voltage, $2200 \mathrm{~V}$.

Treatments. Individual samples (600 g) were baked and the volatiles collected exclusively for identification as previously described (chromatograms not shown). Separate sample volatile profiles were quantitatively and qualitatively compared between 'Centennial' and 'Jewel', using three replications. Likewise, the effect of $\mathrm{O}_{2}$ during baking was similarly tested by comparing carrier gases of $100 \% \mathrm{He}$ with $20 \% \mathrm{O}_{2}$ in $\mathrm{He}$.

Several of the 23 volatile compounds identified (Table 1) have not been identified in earlier studies, e.g., 2,3-dihydro-3,5dihydroxy-6-methyl-4-pyrone and 5- $\mathrm{OH}$ methyl-2-furancarboxaldehyde. Since nine of the compounds identified [compounds numbered $8-11,13,17,18,20$, and 23 (Table 1)] have either pyran or furan rings, they probably are formed from sugars. For instance, 2-furylaldehyde, 2-furmethyl ketone, 2-furmethanol, and 2-methylfuroate have been reported as pyrolyzates of sucrose (Schlotzhauer et al., 1985). Formation of this type of volatile involves hydrolysis of sucrose to monosaccharides, i.e., glucose. After enolization at the $\mathrm{C}_{1}$ and $\mathrm{C}_{2}$ positions, and followed by isomerization and dehydration, various furans and pyranes are formed (see Tressl et al., 1981). However, several volatiles also may have been derived from carotenoids. For example, $\beta$ - cyclocitral (Horvat et al., 1991) and $\beta$-ionone (Purcell et al., 1980) were found in the volatiles from baked 'Jewel' and are known to be formed through the thermal degradation of $\beta$-carotene (Kanasawud and Crouzet, 1990). Thermal degradation of $\beta$ - carotene starts with the addition of epoxides on the end rings of $\beta$ - carotene. Cleavage of both rings results in the formation of 5,6-epoxy $-\beta$ - ionone. Isomerization then leads to the formation of various volatile compounds.
Table 1. Volatiles emanating from baked 'Jewel' sweetpotatoes.

\begin{tabular}{|c|c|c|}
\hline $\begin{array}{l}\text { Com- } \\
\text { pound } \\
\text { no. }^{2}\end{array}$ & $\begin{array}{c}\text { Relative } \\
\text { retention } \\
\text { time }^{y}\end{array}$ & $\begin{array}{l}\text { Volatile } \\
\text { compound }\end{array}$ \\
\hline$\overline{1}$ & 0.24 & 2,3-Pentadione ${ }^{x}$ \\
\hline 2 & 0.35 & Acetol $^{w}$ \\
\hline 3 & 0.47 & 2,3-Butandione ${ }^{w}$ \\
\hline 4 & 0.50 & Methyl propanoate ${ }^{\mathrm{x}}$ \\
\hline 5 & 0.52 & Isobutyl alcohol ${ }^{x}$ \\
\hline 6 & 0.54 & 2-Methyl-2-hexene \\
\hline 7 & 0.56 & Oxabicyclo $(2,2,1)$ heptane ${ }^{x}$ \\
\hline 8 & 0.61 & 2-Furcarboxaldehyde ${ }^{w}$ \\
\hline 9 & 0.71 & 2-Furmethyl ketone \\
\hline 10 & 0.73 & 2-Furmethanol' \\
\hline 11 & 0.76 & Isomaltol ${ }^{w}$ \\
\hline 12 & 0.76 & Benzaldehyde $^{w}$ \\
\hline 13 & 0.84 & 5-Methyl-furfural ${ }^{w}$ \\
\hline 14 & 0.95 & Phenylacetaldehydew \\
\hline 15 & 1.07 & $\beta$-cyclocitral ${ }^{\omega}$ \\
\hline 16 & 1.13 & 2-Acetyl pyrrole ${ }^{x}$ \\
\hline 17 & 1.16 & Maltol' \\
\hline 18 & 1.16 & 2-Methyl-furoate ${ }^{x}$ \\
\hline 19 & 1.26 & $\mathrm{C}_{17}$ hydrocarbon" \\
\hline 20 & 1.29 & $\begin{array}{l}\text { 3,5-Dihydroxy-2-methyl, } \\
\text { 5,6-dihydrogen-4-pyronew }\end{array}$ \\
\hline 21 & 1.37 & $\mathrm{C}_{18}$ hydrocarbon" \\
\hline 22 & 1.49 & $\mathrm{C}_{19}$ hydrocarbon" \\
\hline 23 & 1.66 & $\begin{array}{l}\text { 5-Hydroxymethyl } \\
\text { furylaldehyde }\end{array}$ \\
\hline
\end{tabular}

${ }^{\mathrm{z}}$ Corresponds to the elution sequence from the column.

'Relative retention time (retention time of compound $\mathrm{X} /$ retention time of ethyl benzoate).

${ }^{\mathrm{x}}$ Identified using the mass spectra from the reference library.

"Identified using retention and mass spectral data of authentic compounds.

The isolation procedure used did not yield all of the trace compounds previously identified in the volatiles emanating from baked sweetpotatoes (Kays, 1988). Differences between the present technique and previous reports are most likely due to differences in the trapping and cooking methods used and, to a lesser extent, the chromatography column used. The composite sample collected using the present technique, however, possessed the aromatic properties of baked sweetpotatces. Typically, only a small number of compounds make up the characteristic aroma of fruits and vegetables (Salunke and Do, 1976). The loss of several quantitatively minor peaks did not appear to affect the aromatic properties of the samples.

The reproducibility of the volatile collecting system was analyzed using the coefficient variation within and between four replications. Sample reproducibility assessed variation within each sample, while system reproducibility assessed the variation between samples. For most of the compounds (Table $2)$, the within-sample error and the sample-tosample error estimates were low (i.e., coefficient of variation from 0.9 to 4.7$)$. Two compounds (i.e., 2,3-dihydro-3,5-dihydroxy6-methyl-4-pyrone and 5- $\mathrm{OH}$ - methyl-2furancarboxaldehyde), however, displayed a higher degree of variation. Increased variation may be due to the presence of hydroxy groups that interact with the highly polar GC column. However, the overall reproducibility indicates 
Table 2. Variation within and between replications in quantifying individual volatile compounds.

\begin{tabular}{|c|c|c|c|c|c|c|c|c|c|c|}
\hline \multirow[b]{4}{*}{$\begin{array}{l}\text { Peak } \\
\text { no. }\end{array}$} & \multicolumn{8}{|c|}{ Within-replication variation } & \multirow{3}{*}{\multicolumn{2}{|c|}{$\begin{array}{c}\text { Replication } \\
\text { variation }\end{array}$}} \\
\hline & \multicolumn{8}{|c|}{ Replication } & & \\
\hline & \multicolumn{2}{|c|}{1} & \multicolumn{2}{|c|}{2} & \multicolumn{2}{|c|}{3} & \multicolumn{2}{|c|}{4} & & \\
\hline & $\begin{array}{c}\text { Peak } \\
\text { area } \\
\text { ratio }\end{array}$ & $\mathrm{CV}^{\mathrm{x}}$ & $\begin{array}{l}\text { Peak } \\
\text { area } \\
\text { ratio }\end{array}$ & $\mathrm{CV}$ & $\begin{array}{l}\text { Peak } \\
\text { area } \\
\text { ratio }\end{array}$ & $\mathrm{CV}$ & $\begin{array}{c}\text { Peak } \\
\text { area } \\
\text { ratio }\end{array}$ & $\mathrm{cv}$ & $\begin{array}{c}\text { Peak } \\
\text { area } \\
\text { ratio }\end{array}$ & $\mathrm{CV}$ \\
\hline$\overline{2}$ & 0.13 & 4.69 & 0.12 & 3.22 & 0.13 & 0.62 & 0.12 & 1.88 & 0.13 & 3.94 \\
\hline 8 & 0.97 & 3.51 & 1.02 & 2.49 & 0.92 & 0.99 & 0.79 & 2.32 & 0.93 & 11.1 \\
\hline 9 & 0.07 & 1.91 & 0.07 & 3.87 & 0.06 & 2.05 & 0.05 & 0.45 & 0.06 & 12.7 \\
\hline 10 & 1.47 & 3.23 & 1.41 & 1.99 & 1.35 & 0.70 & 1.25 & 1.99 & 1.37 & 6.8 \\
\hline 13 & 0.12 . & 0.94 & 0.12 & 1.42 & 0.10 & 0.96 & 0.10 & 1.17 & 0.11 & 11.1 \\
\hline 14 & 0.10 & 5.52 & 0.13 & 0.12 & 0.14 & 0.92 & 0.17 & 0.90 & 0.14 & 22.9 \\
\hline 17 & 0.53 & 39.4 & 0.45 & 14.0 & 0.51 & 9.21 & 0.42 & 19.6 & 0.48 & 11.2 \\
\hline 20 & 0.13 & 0.52 & 0.22 & 6.09 & 0.25 & 9.72 & 0.24 & 6.60 & 0.21 & 26.4 \\
\hline 23 & 0.21 & 6.91 & 0.44 & 0.66 & 0.55 & 5.42 & 0.37 & 4.34 & 0.39 & 36.6 \\
\hline
\end{tabular}

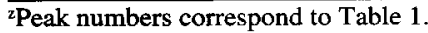

yeak area is the ratio of the peak area of compound $X$ to the peak area of the internal standard; three replications per peak area ratio.

${ }^{x}$ Coefficient of variation, the standard deviation of the ratio of the peak area to the internal standard peak area divided by the mean.

that the technique would be acceptable for quantitatively comparing the volatiles between lines. The major volatiles produced by baked 'Centennial' sweetpotatoes were qualitatively similar to those from 'Jewel' (Table 3). The concentration of phenylacetaldehyde, however, was significantly higher in 'Centennial' volatiles than in 'Jewel'. The similarity in volatile chemistry is not surprising in that the two cultivars are very much alike in flavor.

There was no qualitative difference between the volatiles from 'Jewel' baked either in $\mathrm{He}$ or a $\mathrm{He}-\mathrm{O}_{2}$ mixture; however, four compounds exhibited higher concentrations in He than those produced in $\mathrm{He}-\mathrm{O}_{2}$ mixture (P $\leq$ 0.01; Table 4). Two of the compounds were furancarboxaldehyde (peak 8) and furanmethanol (peak 10). The results indicated that the presence of $\mathrm{O}_{2}$ during cooking may have a slight influence on certain volatiles; however, we detected no perceivable difference between the aromas of both treatments.

The mechanism by which sweetpotatoes produce volatiles is not yet known. However, the presence of what appear to be sugar-derived volatiles indicates the possible involvement of sugars. Additional work is needed to establish the role of specific sugars and other organic compounds in the formation of volatile compounds. Volatile formation may involve enzymatic and/or thermal reactions.

In sweetpotato breeding programs, various selection criteria are used. Traits such as yield, root shape, size, color, and insect and disease resistance are routinely assessed in a sequential order. The number of plants remaining in the population after each trait is selected, therefore, decreases progressively. Currently, flavor evaluation is one of the last, i.e., typically $>99 \%$ of the original lines have been discarded. The low selection pressure for flavor decreases the chances of selecting lines with improved flavor characteristics and greatly impedes developing new flavor types. Use of an analytical approach to screen for flavor (taste and aroma) would increase both the accuracy of selection and the number of lines that can be evaluated (i.e., $\approx 40$ per day). In addition, since flavor preferences often differ substantially from one country to another, a centralized flavor analysis laboratory serving a number of breeding programs would maximize the international effectiveness and impact of each program. Lines that have acceptable flavor characteristics for a country other than where they were developed, but otherwise would have been discarded, can be further tested in countries where they would be acceptable. 'Centennial' sweetpotatoes.

${ }^{2}$ Peaks correspond to thuse presented in Table 1.

${ }^{* *}$ Significantly different between cultivars at $P \leq 0.01$. $\mathrm{He}$ and a $1 \mathrm{O}_{2}: 4 \mathrm{He}$ mixture.

${ }^{2}$ Peaks correspond to those presented in Table 1.

"* Significantly different between cultivars at $P \leq 0.01$.
The development of a standard technique for analyzing aromatic differences between lines of cooked sweetpotatoes represents an important step toward increasing selection pressure for flavor. While additional research is needed, screening parent lines and progeny for flavor in the future is a realistic possibility.

\section{Literature Cited}

Horton, D. 1988. World patterns and trends in sweet potato production. Trop. Agr. 65:268-270.

Horvat, R.J., R.F. Arrendale, G.G. Dull, G.W. Chapman, Jr., and S.J. Kays. 1991. A comparison of the volatile constituents and sugars of three diverse cultivars of sweet potatoes [Ipomoea batatas (L.) Lam.]. J. Food Sci. 56:714-715,742.

Kanasawud, P. and J.C. Crouzet. 1990. Mechanism of formation of volatile compounds by thermal degradation of carotenoids in aqueous medium. 1. $\beta$ - carotene degradation. J. Agr. Food Chem. $38: 237-243$

Kays, S.J. 1985. Formulated sweet potato products, p. 205-218. In: J. Bouwkamp (ed.). Sweet potato products: A natural resource of the tropics. CRC Press, Boca Raton, Fla.

Kays, S.J. 1988. Strategies for selecting conventional and new flavor types of tropical root and tuber crops to increase consumer acceptance and use. Eighth Symp. Intl. Soc. Trop. Root Crops, Bangkok, Thailand. p.178-188.

Kays, S.J. and R.J. Horvat. 1983. Insect resistance and flavor chemistry: Integration into future

Table 3. Comparison of the concentration of individual volatile compounds from baked 'Jewel' and

\begin{tabular}{|c|c|c|c|}
\hline \multirow[b]{2}{*}{$\begin{array}{l}\text { Peak } \\
\text { no. }\end{array}$} & \multirow[b]{2}{*}{$\begin{array}{l}\text { Volatile } \\
\text { compounds }\end{array}$} & \multicolumn{2}{|c|}{ Cultivar } \\
\hline & & $\begin{array}{c}\text { Jewel } \\
\text { mean ratioy }\end{array}$ & $\begin{array}{l}\text { Centennial } \\
\text { mean ratio }\end{array}$ \\
\hline 2 & Acetol & 0.13 & $0.10^{\circ *}$ \\
\hline 8 & 2-Furancarboxaldehyde & 0.93 & 0.75 \\
\hline 9 & 2-Furmethyl ketone & 0.06 & 0.05 \\
\hline 10 & 2-Furanmethanol & 1.37 & $1.59^{* *}$ \\
\hline 13 & 5-Methyl-furfural & 0.11 & $0.07^{* *}$ \\
\hline 14 & Phenylacetaldehyde & 0.14 & $0.34^{* *}$ \\
\hline 17 & Maltol & 0.48 & 0.53 \\
\hline 20 & 2,3-Dihydro-3,5-dihydroxy-6- & & \\
\hline & methyl- $4 H$-pyran-4-one & 0.21 & 0.14 \\
\hline 23 & 5-Hydroxymethyl-2- & & \\
\hline & furancarboxaldehyde & 0.39 & 0.38 \\
\hline
\end{tabular}

y The ratio of the peak area of an individual compound to the peak area of the internal standard.

Table 4. Comparison of the concentration of individual volatiles between 'Jewel' sweetpotatoes baked in

\begin{tabular}{|c|c|c|c|}
\hline \multirow[b]{2}{*}{$\begin{array}{l}\text { Peak } \\
\text { no. }\end{array}$} & \multirow[b]{2}{*}{$\begin{array}{l}\text { Volatile } \\
\text { compound }\end{array}$} & \multicolumn{2}{|c|}{ Mean ratio ${ }^{z}$} \\
\hline & & $\mathrm{He}$ & $\begin{array}{c}20 \% \mathrm{O}_{2} \\
\text { in } \mathrm{He}\end{array}$ \\
\hline 2 & Acetol & 0.13 & $0.10^{* *}$ \\
\hline 8 & 2-Furancarboxaldehyde & 0.93 & $0.65^{* *}$ \\
\hline 9 & 2-Furmethyl ketone & 0.06 & 0.04 \\
\hline 10 & 2-Furanmethanol & 1.37 & $0.94^{* *}$ \\
\hline 13 & 5-Methyl-furfural & 0.11 & $0.07^{* *}$ \\
\hline 14 & Phenylacetaldehyde & 0.14 & 0.13 \\
\hline 17 & Maltol & 0.48 & 0.52 \\
\hline 20 & $\begin{array}{l}\text { 2,3-Dihydro-3,5-dihydroxy- } \\
\text { 6-methyl-4H-pyran-4-one }\end{array}$ & 0.21 & 0.19 \\
\hline 23 & $\begin{array}{l}\text { 5-Hydroxymethyl-2- } \\
\text { furancarboxaldehyde }\end{array}$ & 0.39 & 0.28 \\
\hline
\end{tabular}

"The ratio of the peak arca of an individual compound to the peak area of the internal standard. 
breeding programs. Proc. Amer. Soc. Hort. Sci. Trop. Reg. 27(B):97-106.

Kays, S.J. and R.J. Horvat. 1984. A comparison of the volatile constituents and sugars of representative Asian, Central American, and North American sweet potatoes. 6th Symp. Intl. Soc. Trop. Root Crops, Intl. Potato Center, Lima, Peru. p. 577-586.

McLafferty, F.W. 1988. The Wiley/NBS registry of mass spectral data. 2nd ed. Wiley, New York.

Picha, D.H. 1985. HPLC determination of sugars in raw and baked sweet potatoes. J. Food Sci. 50:1189-1190.
Picha, D.H. 1986. Sugar content of baked sweet potatoes from different cultivars and lengths of storage. J. Food Sci. 51:845-846.

Purcell, A. E., D.W. Later, and M.L. Lee. 1980. Analysis of the volatile constituents of baked 'Jewel' sweet potatoes. J. Agr. Food Chem. 28:939-941.

Salunke, D.K. and J.Y. Do. 1976. Biogenesis of aroma constituents of fruits and vegetables. CRC Crit. Rev. Food Technol. 8:161-190.

Schlotzhauer, W.S., R.F. Arrendale, and O.T. Chortyk. 1985. The rapid pyrolytic character- ization of tobacco leaf carbohydrate material. Beitrage Zur Tabakforschung Intl. 13(2):74-80.

Tiu, C.S., A.E. Purcell, and W.W. Collins. 1985. Contribution of some volatile compounds to sweetpotato aroma. J. Agr. Food Chem. 33:223226.

Tressl, R., K.G. Grünewald, and B. Helak. 1981. Formation of flavour components from proline and hydroxyproline with glucose and maltose and their importance to food flavour, p. 397416. In: P. Schreier (ed.). Flavour '81. Walter de Gruyter, New York. 